\title{
Use of Guarana for Hot Flashes after Breast Cancer: Randomized, Double-Blind, Placebo-Controlled Phase II Trial
}

\author{
Abna Faustina de Sousa Vieira, Vitor Augusto Queiroz Mauad*, Daniel Cubero, Patrícia \\ Xavier Santi and Auro del Giglio
}

Faculdade de Medicina da Fundacao ABC (School of Medicine of the ABC Foundation), AV Lauro Gomes, 2000, Santo Andre, SP, Brazil - 09060-870; vitormauad.medabc@gmail.com

\begin{abstract}
Background: Hot flashes are common in menopausal women and significantly affect the quality of life of many patients diagnosed with breast cancer for which hormone replacement therapy is not indicated. In a previous uncontrolled study, guarana (Paullinia cupana) showed significant decreases in the amount and intensity of hot flashes in this group of women. Hypothesis/Purpose: The main objective was to reduce the intensity and frequency of hot flashes with the use of PC-18, compared with placebo in women who survived breast cancer without current evidence of disease. Study Design: The present study consists of a double-blind, randomized, placebo-controlled, uni-institutional, two-arm phase II clinical trial. Methods: The experimental group received the purified dry extract of Paullinia cupana (PC-18) at a dose of $37.5 \mathrm{~g}$ twice daily, while the other group received placebo, also twice daily. Results: The study included 40 patients who had completed surgical, chemotherapeutic and/or radiotherapeutic treatment for more than 3 months and who were on adjuvant hormone therapy at the time of inclusion, 20 in each arm. Both groups showed significant reductions in the number and intensity of hot flashes, with no significant difference between the arms. There was a higher intensity and frequency of hot flashes in patients receiving tamoxifen compared with those who received aromatase inhibitors. The toxicities observed were not very significant. Conclusion: This concludes that PC-18 did not demonstrate significantly greater capacity than placebo for control of hot flashes in women with a history of breast cancer and adjuvant hormone therapy.
\end{abstract}

Keywords: Breast Neoplasia, Guarana, Hot Flashes, Paullinia cupana

\section{Abbreviations}

NCCN - National Comprehensive Cancer Network.

SSRIs - Selective Serotonin Reuptake Inhibitors.

CYP2D6 - Cytochrome P450 2D6.

PC-18 - Tablets containing the active ingredient guarana, used as intervention.

ADLs - Activities of Daily Life.

HFRDIS - Hot Flashes Related Daily Interference Scale.
ASEX - Arizona Sex Experience Scale.

BECK - Beck's Depression Inventory.

CHALDER - Chalder Fatigue Scale.

EORTC QLQ-30 - European Organisation for the Research and Treatment of Cancer Quality of Life Questionnaire Core 30.

CTCAE - Common Terminology Criteria for Adverse Events.

BMI - Body Mass Index. 


\section{Introduction}

Breast cancer is the most prevalent neoplasm in the worldwide female population. In Brazil, the number of new cases was 59,700 for the year 2018, with a risk of 59.7 cases per 100,000 women $^{20}$. Due to the increased early diagnosis of breast cancer resulting from screening programs ${ }^{5}$ associated with advances in cancer treatment ${ }^{32,36}$, cure rates and survival rates have increased $^{14,24}$. The increase in survival is accompanied by a concern for ensuring the survivors' quality of life ${ }^{40}$. Most patients are treated with chemotherapy followed by hormone therapy for at least 5 years, with current data showing the benefit of extending this therapy for up to 10 years in those with high-risk disease ${ }^{32}$.

Despite the well-documented benefit in overall survival and the decrease in recurrence with such treatments ${ }^{32}$, the side effects, such as hot flashes and sexual dysfunction, affect the quality of life of this population ${ }^{10,17,31}$. Approximately $65 \%$ of treated women suffer from hot flashes, with 59\% of the affected women characterizing the symptom as severe ${ }^{17}$.

Hot flashes are vasomotor symptoms ${ }^{31}$ resulting from the dysfunction of the thermoregulatory center, leading to a decrease in the core temperature threshold required to trigger heat waves. Such dysfunction is caused by decreased serum estrogen levels. While premenopausal women have mechanisms to dissipate heat when the temperature of the thermoregulatory nucleus increases by $0.4^{\circ} \mathrm{C}$, in menopausal women (or those with hypooestrogenism for other reasons), this heat dissipation occurs with much lower temperature increases, leading to hot flashes ${ }^{30}$.

The most effective treatment for hot flashes is hormone replacement with estrogen, reducing the frequency and intensity of these events by $77 \%$ or 2.5 to 3 hot flashes/day ${ }^{33,37}$. The administration of estrogen restores the thermostat to the neutral position, leading to the inhibition of hot flashes. However, due to the formal contraindication of hormone replacement therapy in breast cancer survivors, it is necessary to attempt to use non-hormonal medications to alleviate the symptoms. Some medications have already shown action in the treatment of menopause-related vasomotor symptoms, such as Selective Serotonin Reuptake Inhibitors (SSRIs) fluoxetine and paroxetine ${ }^{26,45}$, norepinephrine and serotonin reuptake inhibitors: venlafaxine ${ }^{11,16,25}$, desvenlafaxine $e^{23,44}$, anticonvulsants (gabapentin) $7,19,38$, megestate $^{18}$, clonidine $e^{6,39}$ and methyldopa ${ }^{2,34}$. Unfortunately, none of these drugs have achieved the rate of reduction achieved by hormone replacement and still present major drawbacks. Because SSRIs are strong inhibitors of CYP2D6, they decrease the formation of endoxifen and activate the metabolite of tamoxifen, leading to a decrease in the plasma concentration of the drug, directly impacting its efficacy.

Other drawbacks are the withdrawal of venlafaxine treatment due to side effects, and the high required dose of gabapentin (>900 mg/day) to achieve a response rate, which determines a higher incidence of side effects such as somnolence ${ }^{38}$. Due to the long-term adverse events associated with a low efficacy in the reduction of hot flashes, many patients and physicians do not use any medications directed against hot flashes, and to date, there is no standard treatment for this symptom.

Guarana (Paullinia cupana, family: Sapindaceae) is an Amazonian plant used for centuries by the local population to treat a headache, poor digestion, kidney dysfunction, muscle pain, menstrual cramps, depression and fatigue. Guarana has already been tested in nononcological populations and has been shown to be beneficial in terms of cognitive performance and mood improvement, being well tolerated at a dose of $75 \mathrm{mg}^{46}$. Studies indicate that the stimulating effect of guarana is not only to the small amount of caffeine, approximately 2.5-5\% present in the dry extract of this plant ${ }^{15,48}$ but perhaps also to other components, such as saponins and tannins ${ }^{29}$.

Paullinia cupana was also tested in oncology patients and has been beneficial in the treatment of cancer-related fatigue in patients undergoing adjuvant chemotherapy for breast cancer in a randomized double-blind study in which non-purified guarana dry extract was used. It was observed that patients who received guarana had a significant decrease in fatigue compared with placebo. Additionally, there was no severe toxicity and there was no worsening of depression or quality of sleep. The results highlight that guarana is an inexpensive and effective therapeutic alternative for the treatment of fatigue induced by chemotherapy ${ }^{8}$.

A pilot study conducted with women taking adjuvant hormone therapy due to breast cancer who had hot 
flashes showed that the use of non-purified dry extract of guarana at a dose of $50 \mathrm{mg}$ twice daily for 6 weeks had significant effects on the amount $(\mathrm{p}=0.0009)$ and intensity $(\mathrm{p}<0.0001)$ of the hot flashes, with great tolerance and there was no discontinuation due to toxicity $^{35}$. However, the interpretation of the efficacy of various agents studied for hot flashes, as exemplified above, are subject to the direct influence of the placebo effect, which is responsible for reducing hot flashes 20 to $50 \%^{41}$. Women with a high degree of anxiety have an even more pronounced version of this placebo effect, responding even more to placebo. Hence, testing all drugs in a placebo-controlled study is of prime importance. Our primary objective was to evaluate the efficacy of a purified dry extract of guarana (PC-18) in reducing the frequency and intensity of hot flashes in patients with a history of breast cancer and adjuvant hormone therapy, comparing the effects produced with those of a group of patients randomized to receive placebo. The secondary objective was to evaluate the efficacy of PC-18 in improving sexual performance, symptoms of depression, fatigue and eventual repercussions of hot flashes and treatment on the quality of life of these patients.

\section{Materials and Methods}

The present study consists of a double-blind, placebo-controlled, randomized, uni-institutional, twoarm clinical trial; one is the experimental group, with the purified dried extract of Paullinia cupana named PC-18 and another being the placebo group.

The planned sample consisted initially of 70 patients recruited from two hospitals (Mario Covas State Hospital and Padre Anchieta Teaching Hospital) who were being followed up at the oncology services of the referred hospitals. Recruitment was performed essentially by an active search of the patients who met the inclusion criteria and were followed up at any of the hospital services mentioned above.

\subsection{Inclusion and Exclusion Criteria}

Patients older than 18 years with a previous diagnosis of luminal breast cancer without current evidence of the disease who had completed the surgical, chemotherapeutic and/or radiotherapeutic treatments for at least 3 months, who were also currently using adjuvant hormone therapy for at least 3 months (either tamoxifen or anastrozole), who reported the presence of at least 1 hot flash per day in the last week or 7 hot flashes per week, who were accessible to study and attended on the scheduled dates for follow-up, who were able to understand the nature and purpose of the study and signed the informed consent form were eligible to participate in the study. Patients with evidence of metastatic disease or local recurrence who had any other cancer diagnosis, with uncontrolled comorbidities, mainly symptomatic hypertension, tachyarrhythmia, hyperthyroidism or heart disease, were excluded from the study.

The study was duly approved by the ethics committee of the School of Medicine of the ABC, to which the two participating hospitals are linked.

\subsection{Study Protocol and Medications used}

In the first visit, the patients received all of the information about the study in question. If they had complained about hot flashes and agreed to participate, they were given a hot flashes diary. Over the course of one week, the patient was instructed to freely record in the diary the time each hot flash occurred throughout the day, its duration, associated symptoms, how much it interfered with what she was doing and whether anything had to be done to improve the symptoms. From these records, the patient would classify each of her hot flashes as mild, moderate, severe or very severe. At the end of that week, the patient was to complete a scale that assesses how much her hot flashes have interfered in her daily activities and in her quality of life.

The second appointment was scheduled one week after the first appointment (week 1) and consisted of the evaluation of the hot flashes diary. If the patient had presented at least 7 hot flashes throughout the week and agreed to participate in the study, the informed consent form was applied. Next, the following parameters were compiled: demographic characteristics of the patient, such as ethnicity, age, schooling, occupation, marital status, menopausal status, whether the patient had an active sexual life and whether hot flashes interfered with her quality of life. Data on the diagnosis and treatment of breast cancer, such as date of diagnosis, histological type, initial clinical staging, whether the patient had undergone surgery and when, whether chemotherapy 
bad been performed and when, whether radiotherapy had been performed and when, date when hormone therapy was initiated and the medication is chosen for this purpose, were also collected. In the second consultation, 4 questionnaires were also provided to the patients.

The PC-18 used was the standardized dry extract of Paullinia cupana (PGUR0062F), obtained by extraction in $70 \%$ alcohol and after evaporation, the pure extract containing $0.096 \%$ of the obromine was obtained. The placebo was given to the patients inside containers and capsules similar to those of PC-18, and it was composed of $100 \%$ cornstarch.

Patients were randomized into 2 groups: Group 1 and group 2. Group 1 received treatment with tablets containing the active ingredient of guarana (PC-18) at a dose of $37.5 \mathrm{mg} /$ tablet $2 \mathrm{x}$ daily for 4 weeks; group 2 received treatment with placebo tablets for 4 weeks. This dosing was based upon a previous article by Oliveira SS et al that made use of an impurified extract at $50 \mathrm{mg} \mathrm{q} 12$ $\mathrm{h}$ daily. Dose was adjusted to $37.5 \mathrm{mg}$ q12h, considering the concentration of the PC-18 compound, against the impurified extract used on the referenced article. The patients received 56 tablets containing guarana or placebo according to the group to which they had been randomly allocated in a double-blind fashion.

For 4 weeks (from the beginning of week 1 to the end of week 4), patients in group 1 and 2, respectively, used PC-18 and placebo. At the third appointment (week 5), the hot flashes diaries that were already completed were delivered by the patient and once again, the questionnaires described below were answered. At that time, the patients returned the medicine bottle; the remaining capsules were counted to determine the lack of use of the medication. There was no crossover (Figure 1).

\subsection{Evaluation Tools}

The instrument chosen to evaluate the frequency and severity of hot flashes was the same one used by Loprinzi $\mathrm{CL}^{9,26,42}$. Over the course of one week, the patient observed the number of hot flashes, their duration, whether they interfered with their Activities of Daily Life (ADLs) and if anything was needed to improve the symptoms. From this observation, the patient should note how many hot flashes a day she considered mild (without interference in ADLs), moderate (little interference in ADLs), severe (so uncomfortable that ADLs could not be performed) or very severe (so uncomfortable that ADLs could not be performed and the patient needed to do something to reverse the symptoms) intensity. The frequency was calculated from the average number of hot flashes/day that the patient presented during the week. The severity was calculated from a score obtained by multiplying the number of hot flashes by their respective severity (if light, multiplied by 1 ; if moderate, by 2 ; if severe, by 3 ; and if very severe, by 4 ). The result of the score corresponds to the sum of these products.

In addition, to evaluate more precisely how hot flashes interfered with daily activities and patient quality of life, a questionnaire was used that evaluates, through a scale from 0 (does not interfere) to 10 (interferes completely), how much the hot flashes interfered in 9 aspects of the patient's life (work, social activities, leisure activities, sleep, mood, concentration, relation with others, sexuality, enjoyment of life) and finally, interference in quality of life as a whole. This scale is the Portuguese version of the scale originally in English (Annex 2) called "The Hot Flashes Related Daily Interference ScaleHFRDIS”, created and validated by ${ }^{9}$.

To evaluate the possible interference of PC-18 in sex drive, depression, quality of life and fatigue, the respective questionnaires $\mathrm{ASEX}^{27,28}$, the BECK scale ${ }^{3,4}$, EORTC QLQ-30 $0^{1,43,12}$, previously validated for Portuguese, were used.

ASEX was developed to evaluate psychotropic medication-induced sexual dysfunction. This instrument has previously been validated for use in Brazilian cancer patients ${ }^{22}$. ASEX is a five-question short questionnaire designed to measure sexual functioning in 5 domains. The items are scored on a 6-point scale, ranging from 1 (hyperfunction) to 6 (hypofunction), with a total score ranging from 5 to 30 . A total score $>18$, a score $\geq 5$ (very difficult) on any of the items or three items with an individual score $\geq 4$ are indicative of clinically significant sexual dysfunction ${ }^{27,28}$.

The Beck Depression Scale consists of a self-report questionnaire with 21 multiple choice items and is one of the instruments most used to measure the severity of depressive episodes. It covers 21 premises referring to the current moment of the subject that are quantified on a scale of 4 intensity points ( 0 to 3 ). The instrument is 


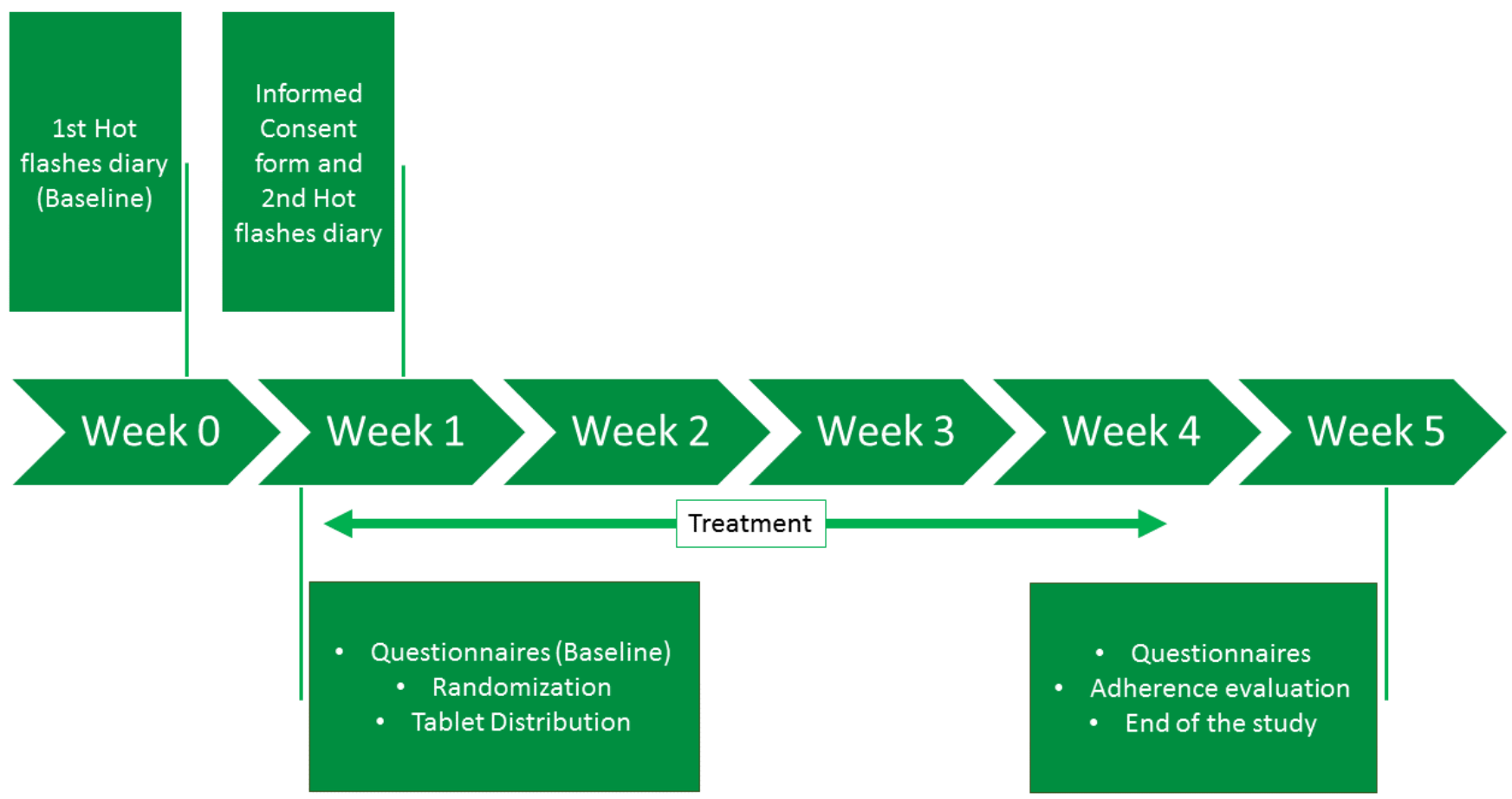

Figure 1. Protocol for the study.

easy to manipulate and apply and has great acceptance. The scores range from 0 to 63 , where zero indicates there is no trace of depression and higher scores indicate greater severity of depression. The interpretation guide is as follows: $1.0=$ Minimal score, no depression; 2. 10 to $16=$ Mild to moderate state of depression; 3 . 17 to $29=$ oderate to severe state of depression; and 4.30 to $63=$ Indicates a severe state of depression ${ }^{3,4}$.

Version 3.0 of the QLQ-C30 consists of 5 functional scales, 2 symptom scales, 1 global health status scale and 6 unique items. All scales range from 0 to 100; thus, a high score for a functional scale represents a high level of healthy functioning and a high score for the overall health status represents a high quality, but a high score for a scale/item of symptom represents a high level of symptomatology, which translates into a poor response. The answers are coded in the same way as in items 1 to 28, i.e., "No", "Little", "Yes " and "Very Much"; questions 29 and 30 are scored on a numerical scale from 1 to $73^{1,43}$.

The Chalder scale consists of 11 questions. Questions 1-10 have the standardized responses of "Less than usual", "No more than usual", "More than usual" and "Much more than usual"; question 11 has the standardized responses "Better than usual", "No worse than usual", "Worse than usual" and "Much worse than usual". The score is assigned from 0 to 33 points (Chalder et al., 1993). Toxicities were assessed according to CTCAE version 4.0 (CTCAE versao 4.0).

\section{Statistical Analysis}

First, the sample calculation was based on the prevalence of hot flashes among post-breast cancer women of $65 \%{ }^{17}$, with a possible variation of this frequency of $10 \%$, with a study power of $80 \%$ and a significance level of $5 \%$, considering the possibility of $20 \%$ loss. The sample planning also contemplated an interim analysis when the recruitment reached $50 \%$ of the predicted number, that is, 35 patients.

We analyzed the means of the frequency of the hot flashes and the product of the frequency by the intensity of the hot flashes, which were compared between the groups that received PC-18 and placebo by Student's T-test or the Wilcoxon test, depending on the normality or otherwise of the samples. Likewise, we analyzed the differences between groups for the Quality of Life EORTC 
QLQ C-30, Beck, ASEX and Chalder questionnaire scores. We considered the values of $p$ that were less than or equal to 0.05 as significant.

\section{Results}

In our study, after reaching 40 patients, an interim analysis was performed, as predicted in the statistical planning. Of the 40 patients, 2 were followed up for neoplasia at the Mario Covas State Hospital, Santo Andre-SP and 38 were followed up for neoplasia at the Padre Anchieta Teaching Hospital, Sao Bernardo do Campo-SP. The analysis of the demographic characteristics showed that

Table 1. Table of characteristics

\begin{tabular}{lcc}
\hline & PC-18 & Placebo \\
\hline Age & & \\
Average (Range) & $53(37-70)$ & $52.2(43-77)$ \\
St Dev & 9,5 & 7,9 \\
BMI & & \\
Average & $26(19,5-45,3)$ & $29,5(17-45,3)$ \\
Median & 25,7 & 28,8 \\
St Dev & 4 & 6,1 \\
Menopause & & \\
Yes & 18 & 16 \\
No & 2 & 4 \\
Medication & & \\
Anastrozol & 10 & 5 \\
Tamoxifen & 10 & 15 \\
Chemotherapy & & \\
Yes & 16 & 18 \\
No & 4 & 2 \\
Radiotheraphy & & \\
Yes & 14 & 14 \\
No & 6 & 6 \\
\hline Tabagism & & \\
Yes & 1 & 3 \\
No & 19 & 17 \\
\hline Ethinicity & & \\
White & 9 & \\
Brown & 10 & \\
African Decendent & & \\
\hline & & \\
\hline
\end{tabular}

both arms were comparable; there was no significant difference between them (Table 1).

The mean ages were 53 years in the intervention group and 52.25 in the control group. Regarding medication, most patients in the control group used tamoxifen as hormone therapy, 15 (75\%) compared with only 10 (50\%) in the intervention group, but with no significant difference between them $(\mathrm{p}=0.1)$.

All questionnaires were answered by all patients, with the exception of the hot flashes diary, which was not answered by only 1 patient.

For the primary outcome, the hot flashes diary was the main score. In week 0 , all 20 patients in the placebo group and 19 in the study group completed the questionnaire; these numbers decreased with the progression of the week, with 16 and 13 at week $1 ; 15$ and 13 at week 2; 15 and 12 at week 3 ; and 15 and 12 at weeks 4 and 5 .

In our study, both arms showed significant reductions in the number and intensity of hot flashes, showing, as already mentioned above, the weight of the placebo effect in this population. The frequency and intensity curves with each week of medication use, showed a progressive decrease, with greater expression in the first week of intervention (Figures 2 and 3).

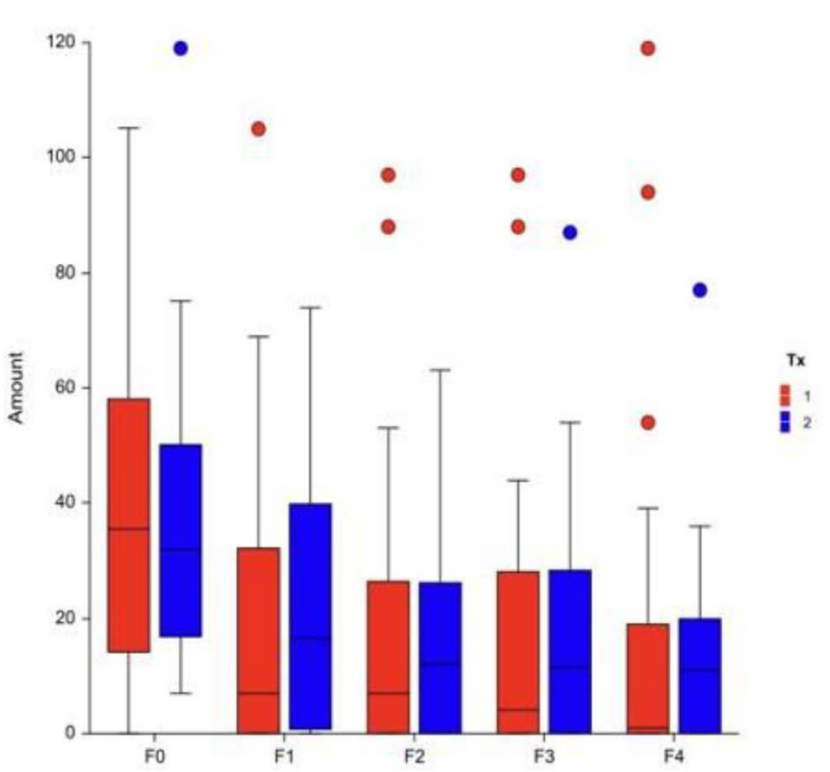

Figure 2 Chart for Frequency of Episodes. PC-18 = 1; Placebo $=2$ 


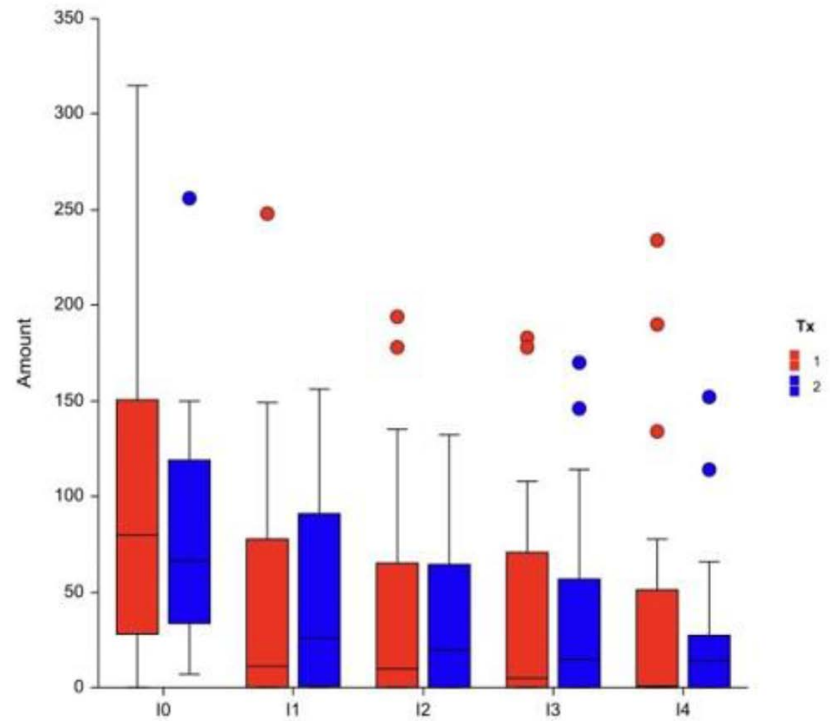

Figure 3. Chart for intensity of episodes. PC-18 = 1; Placebo $=2$

However, when comparing the placebo group with the intervention group (PC-18), there were no significant differences in relation to each other for either frequency $(\mathrm{p}=0.54)$ or intensity $(\mathrm{p}=0.84)$.

The results for the scores related to the secondary objectives resulted in $\mathrm{p}=0.42$ for the hot flashes scale and quality of life, $\mathrm{p}=0.6$ for the ASEX scale (Figure 4), $\mathrm{p}=0.09$ for the BECK scale (Figure 5) and $\mathrm{p}=0.18$ for the CHALDER scale (Figure 6). Finally, the quality of life assessed through the EORTC QLQ 30 scale (Figure 7) did not show a statistically significant difference between the groups.

By observing the data set, significant differences in the intensity and frequency of hot flashes were observed between patients using anastrozoleor tamoxifen ( $p$ $=0.0017$ ), with a mean of 3.7 episodes per day for anastrozoleand 6.7 for tamoxifen. The weekly intensity score for week 0 was almost double that of tamoxifen (57.2 vs. $104, \mathrm{p}=0.0075$ ).

The adverse effects that were observed are listed in Table 2. It is worth noting that patients who had grade 3 and grade 4 adverse effects already had such symptoms prior to recruitment. PC-18 was at least as well tolerated as placebo, with 9 patients reporting G3 toxicity, 4 of which were for sweating and 2 for fatigue, which was not enough to interrupt the protocol.

\section{Discussion}

Women with breast cancer ${ }^{17}$ often have hot flashes because they become abruptly deficient in estrogen due to either chemotherapy leading to premature ovarian failure or bilateral oophorectomy. In addition, many of these women receive hormone therapy for breast cancer treatment that can also intensify hypo-oestrogenism.

The sensation of heat is the result of an inappropriate peripheral vasodilatation, with increased cutaneous blood flow. The observation that prepubescent girls, whose estrogen levels are very low, do not have hot flashes proves that hypo-oestrogenism alone is not responsible for producing hot flashes. It is believed that exposure to adult levels of estrogen, followed by a rapid decrease inestrogen levels, is necessary for the hot flashes to occur ${ }^{30,31}$.

Hot flashes not only have a negative impact on quality of life but are also associated with adverse health indicators (increased cardiovascular risk and increased risk of bone loss) ${ }^{47}$. These associations make the search for an effective treatment for hot flashes of paramount importance.

It is worth remembering that in women with a history of breast cancer, systemic estrogen replacement

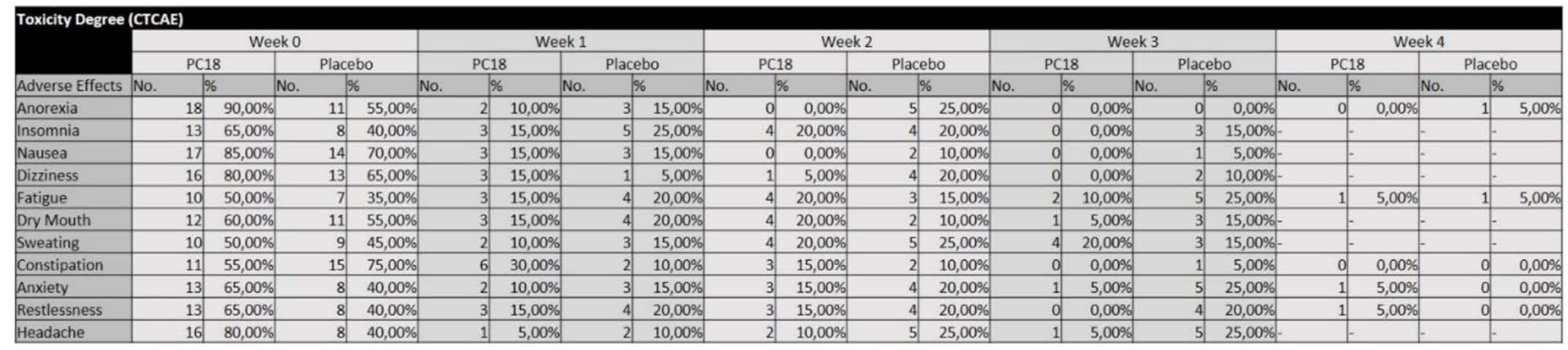

Table 2. Table of adverse effects 

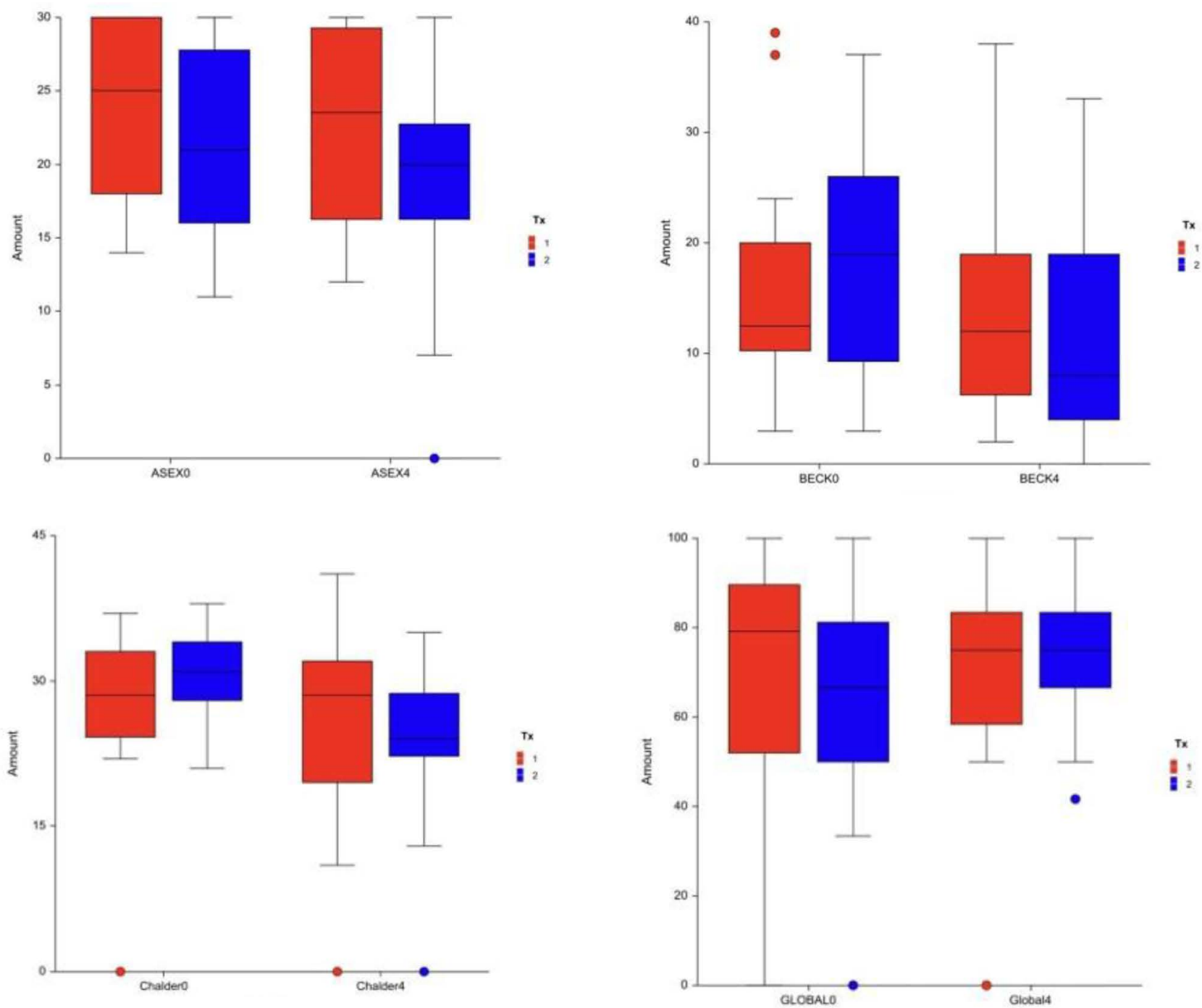

Figures 4 to 7: Charts for score outcomes, each chart target score specified on the $x$ axis. $P C-18=1 ; P l a c e b o=2$

is formally contraindicated. Thus, one can make use of non-pharmacological measures (in cases of mild to moderate episodes) and/or therapeutic interventions (in severe to very severe cases), many of which have several adverse effects and may even lead to the decreased action of tamoxifen, as with SSRIs.

The use of tamoxifen was associated with hot flashes in up to $80 \%$ of patients, $30 \%$ of which classified such episodes as severe ${ }^{17}$. Genetic characteristics ofestrogen receptors may also influence the risk and intensity of tamoxifen-induced hot flashes. Aromatase inhibitors may also lead to hot flashes, but they tend to be less frequent and less severe ${ }^{21,22}$, as also observed in this study.
The great influence of the placebo effect on hot flashes cannot be ruled out, underscoring the need for placebocontrolled trials. In fact, the interpretation of the efficacy of the various agents studied for hot flashes is influenced by the placebo effect, which is responsible for reducing the frequency of hot flashes from 20 to $50 \%{ }^{48}$. This effect is even more significant in women with a high degree of anxiety, suggesting that even active agents with proven statistical significance can act, at least in part, through the placebo effect mechanism.

In this study, although the group of patients receiving PC-18 had significant decreases in the number and intensity of hot flashes during the study, the decreases were not significantly greater than those seen in the 
placebo group. Likewise, we did not observe significant changes in the scores of the other questionnaires analyzed (ASEX, Chalder, QLQ C-30 and Beck) among patients receiving PC-18 and placebo. This fact reinforces the need to always include a placebo group in studies that seek pharmacological relief of symptoms, as we did in this study.

The absence of a trend favoring PC-18 led us to suspend this study in the first interim analysis, scheduled for when the study reached half of the total planned sample. Based on the results obtained in this study, we could not suggest the use of guarana to reduce hot flashes in this patient population.

\section{Supplementary Data}

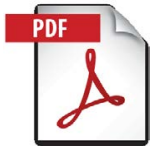

\section{Funding}

Funding for this study was provided through the Centre for Study and Research in Haematology and Oncology (CEPHO), an institution related to the ABC Medical School and Haematology/ Oncology chair.

\section{Role of the Funding Source}

CEPHO assisted on providing the funding for intervention and placebo elaboration. All other costs where funded by the authors themselves.

\section{Declarations of Interest}

The authors confirm that there are no known conflicts of interest associated with this publication and there has been no significant financial support for this work that could have influenced its outcome.

\section{References}

1. Aaronson NK, Ahmedzai S, Bergman B, Bullinger M, Cull A, Duez NJ, Filiberti A, Flechtner H, Fleishman SB, de Haes JC. The European organization for research and treatment of cancer QLQ-C30: A quality-of-life instrument for use in international clinical trials in oncology. J. Natl Cancer Inst. 1993; 85:365-76. PMid: 8433390. https://doi.org/10.1093/jnci/85.5.365

2. Andersen O, Engebretsen T, Solberg VM, Orbo A. a-Methyldopa for climacteric hot flushes: A doubleblind, randomized, cross-over study. Acta Obstet Gynecol Scand. 1986; 65:405-9. PMid: 3535358. https://doi. org/10.3109/00016348609157373

3. Andrade L, Gorenstein C, Filho AHV, Tung TC, Artes R. Psychometric properties of the Portuguese version of the State-Trait Anxiety Inventory applied to college students: Factor analysis and relation to the Beck Depression Inventory. Braz J Med Biol Res. 2001; 34:367-74. PMid: 11262588. https://doi.org/10.1590/S0100-879X2001000300011

4. Beck AT, Steer RA. Internal consistencies of the original and revised beck depression inventory. J Clin Psychol. 1984; 40:1365-7. https://doi.org/10.1002/1097-4679(198411)40:6 < 1365::AID-JCLP2270400615>3.0.CO;2-D

5. Berry DA, Cronin KA, Plevriti, SK, Fryback DG, Clarke L, Zelen M, Mandelblatt JS, Yakovlev AY, Habbema JDF, Feuer EJ. Effect of screening and adjuvant therapy on mortality from breast cancer. New Engl J Med. 2005; 353:1784-92. PMid: 16251534. https://doi.org/10.1056/NEJMoa050518

6. Buijs $\mathrm{C}$, Mom $\mathrm{CH}$, Willemse PHB, Boezen HM, Maurer JM, Wymenga ANM, de Jong RS, Nieboer P, de Vries EGE, Mourits MJE. Venlafaxine versus clonidine for the treatment of hot flashes in breast cancer patients: A double-blind, randomized cross-over study. Breast Cancer Res Treat. 2008; 115:573-80. PMid18670875. https://doi.org/10.1007/s10549008-0138-7

7. Butt DA, Lock M, Lewis JE, Ross S, Moineddin R. Gabapentin for the treatment of menopausal hot flashes: A randomized controlled trial. Menopause. 2008; 15:310-8. PMid: 17917611. https://doi.org/10.1097/gme.0b013e3180dca175

8. Campos MP, Riechelmann R, Martins LC, Hassan BJ, Casa FB, Del Giglio A. Effect of guarana (Paullinia cupana) on fatigue in breast cancer patients undergoing systemic chemotherapy. J Clin Oncol. 2010; 28:9007. https://doi.org/10.1200/ jco.2010.28.15_suppl.9007

9. Carpenter JS. The hot flash related daily interference scale: A tool for assessing the impact of hot flashes on quality of life following breast cancer. J Pain Symptom Manag. 2001; 22:979-89. https://doi.org/10.1016/S0885-3924(01)00353-0

10. Carpenter JS, Johnson DH, Wagner LJ, Andrykowski MA. Hot flashes and related outcomes in breast cancer survivors and matched comparison women. Oncol Nurs Forum. 2002; 29:E16-25. PMid: 11979290. https://doi.org/10.1188/02. ONF.E16-E25

11. Carpenter JS, Storniolo AM, Johns S, Monahan PO, Azzouz F, Elam JL, Johnson CS, Shelton RC. Randomized, double-blind, placebo-controlled crossover trials of venlafaxine for hot flashes after breast cancer. Oncologist. 2007; 
12:124-35. PMid: 17227907. https://doi.org/10.1634/theoncologist.12-1-124

12. Chalder T, Berelowitz G, Pawlikowska T, Watts L, Wessely S, Wright D, Wallace EP. Development of a fatigue scale. J Psychosom Res. 1993; 37:147-53. https://doi. org/10.1016/0022-3999(93)90081-P

13. CTCAE versão 4.0. https://ctep.cancer.gov/protocoldevelopment/electronic_applications/ctc.htm.

14. Early Breast Cancer Trialists' Collaborative Group (EBCTCG), 2005. Effects of chemotherapy and hormonal therapy for early breast cancer on recurrence and 15-year survival: An overview of the randomised trials. Lancet. 2005; 365:1687717. https://doi.org/10.1016/S0140-6736(05)66544-0

15. Espinola EB, Dias RF, Mattei R, Carlini EA. Pharmacological activity of Guarana (Paullinia cupana Mart.) in laboratory animals. J Ethnopharmacol. 1997; 55:223-9. https://doi. org/10.1016/S0378-8741(96)01506-1

16. Evans ML, Pritts E, Vittinghoff E, McClish K, Morgan KS, Jaffe RB. Management of postmenopausal hot flushes with venlafaxine hydrochloride: A randomized, controlled trial. Obstet. Gynecol. 2005; 105:161-6. PMid: 15625158. https:// doi.org/10.1097/01.AOG.0000147840.06947.46

17. Ganz PA, Desmond KA, Leedham B, Rowland JH, Meyerowitz BE, Belin TR. Quality of life in long-term, disease-free survivors of breast cancer: A follow-up study. J Natl Cancer Inst. 2002; 94:39-49. PMid: 11773281. https://doi.org/10.1093/jnci/94.1.39

18. Goodwin JW, Green SJ, Moinpour CM, Bearden JD, Giguere JK, Jiang CS, Lippman SM, Martino S, Albain KS. Phase III randomized placebo-controlled trial of two doses of megestrol acetate as treatment for menopausal symptoms in women with breast cancer: Southwest oncology group study 9626. J Clin Oncol. 2008; 26:1650-6. PMid: 18375894. https://doi. org/10.1200/JCO.2006.10.6179

19. Guttuso T, Kurlan R, McDermott MP, Kieburtz K. Gabapentin's effects on hot flashes in postmenopausal women: A randomized controlled trial. Obstet Gynecol. 2003; 101:337-45. https://doi.org/10.1016/S0029-7844(02)02712-6

20. Instituto Nacional de Cancer Jose Alencar Gomes da Silva. Estimativa 2018: Incidencia de Cancer no Brasil. INCA, Rio de Janeiro. 2018.

21. Jin Y, Hayes DF, Li L, Robarge JD, Skaar TC, Philips S, Nguyen A, Schott A, Hayden J, Lemler S, Storniolo AM, Flockhart DA, Stearns V. Estrogen receptor genotypes influence hot flash prevalence and composite score before and after tamoxifen therapy. J Clin Oncol. 2008; 26:5849-54. PMid: 19018086 PMCid: PMC2645113. https://doi.org/10.1200/ JCO.2008.16.8377

22. Jones SE, Cantrell J, Vukelja S, Pippen J, O’Shaughnessy J, Blum JL, Brooks R, Hartung NL, Negron AG, Richards DA, Rivera R, Holmes FA, Chittoor S, Whittaker TL, Bordelon JH, Ketchel SJ, Davis JC, Ilegbodu D, Kochis J, Asmar L. Comparison of menopausal symptoms during the first year of adjuvant therapy with either exemestane or tamoxifen in early breast cancer: Report of a tamoxifen exemestane adjuvant multicenter trial substudy. J Clin Oncol. 2007; 25:4765-71. PMid: 17947724. https://doi.org/10.1200/JCO.2007.10.8274

23. Kagan R, Constantine G, Olivier S. Treatment with Desvenlafaxine Succinate (DVS) results in a sustained reduction in number of severe Hot Flushes (HFs) in menopausal women. Menopause. 2007; 14:1084-4.

24. Kawamura T, Sobue T. Comparison of breast cancer mortality in five countries: France, Italy, Japan, the UK and the USA from the WHO mortality database (1960-2000). Jpn J Clin Oncol. 2005; 35:758-9. PMid. 16377739. https://doi. org/10.1093/jjco/hyi201

25. Loprinzi CL, Kugler JW, Sloan JA, Mailliard JA, LaVasseur BI, Barton DL, Novotny PJ, Dakhil SR, Rodger K, Rummans TA, Christensen BJ. Venlafaxine in management of hot flashes in survivors of breast cancer: A randomised controlled trial. Lancet. 2000; 356:2059-63. https://doi.org/10.1016/S01406736(00)03403-6

26. Loprinzi CL, Sloan JA, Perez EA, Quella SK, Stella PJ, Mailliard JA, Halyard MY, Pruthi S, Novotny PJ, Rummans TA. Phase III evaluation of fluoxetine for treatment of hot flashes. J Cli. Oncol. 2002; 20:1578-83. PMid: 11896107. https://doi.org/10.1200/JCO.2002.20.6.1578

27. Mathias C, Athanazio RA, Braghiroli MI, Nu-ez G, Lessa R, Macedo G, Sena EPD, Del Giglio A. Uso da escala de experiencia sexual do Arizona (ASEX) na avaliacao de disfuncao sexual em pacientes oncologicos brasileiros. J Bras Psiquiatr. 2005; 54:216-20.

28. McGahuey CA, Gelenberg AJ, Laukes CA, Moreno FA, Delgado PL, McKnight KM, Manber R. The Arizona sexual experience scale (ASEX): Reliability and validity. J Sex Marital Ther. 2000; 26:25-40. PMid: 10693114. https://doi. org/10.1080/009262300278623

29. Miranda MV, Metzner BS. Paullinia cupana: Revisao da materia medica. Rev Homeopat. 2010; 73:1-17.

30. Morrow PKH, Mattair DN, Hortobagyi GN. Hot flashes: A review of pathophysiology and treatment modalities. Oncologist. 2011; 16:1658-64. PMid: 22042786 PMCid: PMC3233302. https://doi.org/10.1634/theoncologist.2011-0174

31. Mortimer JE, Boucher L, Baty J, Knapp DL, Ryan E, Rowland JH. Effect of tamoxifen on sexual functioning in patients with breast cancer. J Clin Oncol. 1999; 17:1488-8. PMid: 10334535. https://doi.org/10.1200/JCO.1999.17.5.1488

32. NCCN Guidelines version 3, 2017. https:/www.nccn.org/ professionals/physician_gls/pdf/breast.pdf

33. Nelson HD. Commonly used types of postmenopausal estrogen for treatment of hot flashes: Scientific review. JAMA. 2004; 291:1610-20. https://doi.org/10.1001/ jama.291.13.1610 
34. Nesheim BI, Stre T. Reduction of menopausal hot flushes by methyldopa: A double blind crossover trial. Eur J Clin Pharmacol. 1981; 20:413-6. PMid: 7026262. https://doi. org/10.1007/BF00542092

35. Oliveira SS, del Giglio AB, Lerner TG, Zanellato RM, Tiemi L, Reifur L, Santi PX, del Giglio A. Paullinia cupana for control of hot flashes in breast cancer patients: A pilot study. Einstein. 2013; 11:435-8. PMCid: PMC4880378. https://doi. org/10.1590/S1679-45082013000400005

36. Overgaard M, Jensen MB, Overgaard J, Hansen PS, Rose C, Andersson M, Kamby C, Kjaer M, Gadeberg CC, Rasmussen BB, Blichert-Toft M, Mouridsen HT. Postoperative radiotherapy in high-risk postmenopausal breast-cancer patients given adjuvant tamoxifen: Danish breast cancer cooperative group DBCG 82c randomised trial. Lancet. 1999; 353:16418. https://doi.org/10.1016/S0140-6736(98)09201-0

37. Pachman DR, Jones JM, Loprinzi CL. Management of menopause-associated vasomotor symptoms: Current treatment options, challenges and future directions. Int J Womens Health. 2010; 2:123-35. PMid: 21072305 PMCid: PMC2971731.

38. Pandya KJ, Morrow GR, Roscoe JA, Zhao H, Hickok JT, Pajon E, Sweeney TJ, Banerjee TK, Flynn PJ. Gabapentin for hot flashes in 420 women with breast cancer: A randomised double-blind placebo-controlled trial. Lancet. 2005; 366:81824. https://doi.org/10.1016/S0140-6736(05)67215-7

39. Pandya KJ, Raubertas RF, Flynn PJ, Hynes HE, Rosenbluth RJ, Kirshner JJ, Pierce HI, Dragalin V, Morrow GR. Oral clonidine in postmenopausal patients with breast cancer experiencing tamoxifen-induced hot flashes: A university of rochester cancer center community clinical oncology program study. Ann Intern.Med. 2000; 132:788-93. PMid: 10819701. https://doi. org/10.7326/0003-4819-132-10-200005160-00004

40. Peto R, Boreham J, Clarke M, Davies C, Beral V. UK and USA breast cancer deaths down $25 \%$ in year 2000 at ages $20-69$ years. Lancet. 2000; 355:1822. https://doi.org/10.1016/S01406736(00)02277-7

41. Santen RJ, Stuenkel CA, Davis SR, Pinkerton JV, Gompel A, Lumsden MA. Managing menopausal symptoms and associated clinical issues in breast cancer survivors. J Clin
Endocrinol Metab. 2017; 102:3647-61. PMid: 28934376. https://doi.org/10.1210/jc.2017-01138

42. Sloan JA, Loprinzi CL, Novotny PJ, Barton DL, Lavasseur BI, Windschitl H. Methodologic lessons learned from hot flash studies. J Clin Oncol. 2001; 19:4280-90. PMid: 11731510. https://doi.org/10.1200/JCO.2001.19.23.4280

43. Soares HP, Zatta SM, Bezerra AS, Wroclawski ML, Pertusier LO, Giglio A. Aplicacao dos questionarios de qualidade de vida "FLIE" e "EORTC QLQ C-30" para pacientes oncologicos em tratamento quimioterapico: Estudo piloto da Disciplina de Oncologia e Hematologia da Faculdade de Medicina da Fundacao ABC. Rev Soc Bras Cancerol. 2001; 15:19.

44. Speroff L, Gass M, Constantine G, Olivier S, Study 315 Investigators. Efficacy and tolerability of desvenlafaxine succinate treatment for menopausal vasomotor symptoms: A randomized controlled trial. Obstet Gynecol. 20081 111:77-87. PMid: 18165395. https://doi.org/10.1097/01. AOG.0000297371.89129.b3

45. Stearns V, Beebe KL, Iyengar M, Dube E. Paroxetine controlled release in the treatment of menopausal hot flashes: A randomized controlled trial. JAMA. 2003; 289:2827-34. PMid: 12783913. https://doi.org/10.1001/ jama.289.21.2827

46. Tfouni SAV, Camargo MCR, Vitorino SHP, Menegario TF, Toledo MCDF. Contribuicao do guarana em po (Paullinia cupana) como fonte de cafeína na dieta. Rev Nutr. 2007; 20:63-8. https://doi.org/10.1590/S1415-52732007000100007

47. Thurston RC, Sutton-Tyrrell K, Everson-Rose SA, Hess R, Matthews KA. Hot flashes and subclinical cardiovascular disease: Findings from the study of women's health across the nation heart study. Circulation. 2008; 118:1234-40. PMid: 18765392 PMCid: PMC2728044. https://doi.org/10.1161/ CIRCULATIONAHA.108.776823

48. Weckerle CS, Stutz MA, Baumann TW. Purine alkaloids in Paullinia. Phytochemistry. 2003; 64:735-42. https://doi. org/10.1016/S0031-9422(03)00372-8

49. Young-McCaughan S. Sexual functioning in women with breast cancer after treatment with adjuvant therapy. Cancer Nurs. 1996; 19:308-19. PMid: 8768689. https://doi. org/10.1097/00002820-199608000-00007 